\title{
Serum Plant Sterols Associate with Gallstone Disease \\ Independent of Weight Loss and Non-Alcoholic Fatty Liver Disease
}

\section{Kakela, Pirjo}

2017-05

Kakela , P, Mannisto , V , Ilves , I , Vaittinen , M , Tauriainen, M-M , Eskelinen, M , Gylling , H, Paajanen, H \& Pihlajamaki , J 2017 , ' Serum Plant Sterols Associate with Gallstone Disease Independent of Weight Loss and Non-Alcoholic Fatty Liver Disease ' , Obesity Surgery , vol. 27 , no. 5 , pp. 1284-1291 . https://doi.org/10.1007/s11695-016-2446-z

http://hdl.handle.net/10138/236800

https://doi.org/10.1007/s11695-016-2446-z

publishedVersion

Downloaded from Helda, University of Helsinki institutional repository.

This is an electronic reprint of the original article.

This reprint may differ from the original in pagination and typographic detail.

Please cite the original version. 


\title{
Serum Plant Sterols Associate with Gallstone Disease Independent of Weight Loss and Non-Alcoholic Fatty Liver Disease
}

\author{
Pirjo Käkelä $^{1}$ • Ville Männistö ${ }^{2}$ - Imre Ilves ${ }^{1} \cdot$ Maija Vaittinen $^{3}$. \\ Milla-Maria Tauriainen ${ }^{2}$ - Matti Eskelinen ${ }^{1}$ - Helena Gylling ${ }^{3,4}$ • Hannu Paajanen ${ }^{1}$ • \\ Jussi Pihlajamäki ${ }^{3,5}$
}

Published online: 3 November 2016

(C) Springer Science+Business Media New York 2016

\begin{abstract}
Background Gallstone disease (GD) has been associated with low serum levels of plant sterols. We evaluated the impact of laparoscopic Roux-en-Y gastric bypass (LRYGB) and nonalcoholic fatty liver disease (NAFLD) on the association of GD with low levels of serum plant sterols.

Methods Two hundred forty-two consecutive morbidly obese patients were recruited to this prospective study. Histological analysis of liver biopsy to diagnose NAFLD was performed. Bile sample was taken during the LRYGB. Associations of GD with serum non-cholesterol sterol to cholesterol ratios, measured using gas liquid chromatography and with mRNA expression of genes participating in the cholesterol, bile, and fatty acid metabolism in the liver, were analyzed.

Results Out of the 242 participants, 95 had GD. Lower weight $(p=0.002)$ and female sex $(p=0.0006)$ were associated with
\end{abstract}

Electronic supplementary material The online version of this article (doi:10.1007/s11695-016-2446-z) contains supplementary material, which is available to authorized users.

Jussi Pihlajamäki

jussi.pihlajamaki@uef.fi

1 Department of Surgery, Kuopio University Hospital, University of Eastern Finland, Kuopio, Finland

2 Departments of Medicine, Kuopio University Hospital, University of Eastern Finland, Kuopio, Finland

3 Institutes of Public Health and Clinical Nutrition, University of Eastern Finland, 70210 Kuopio, Finland

4 Helsinki University Central Hospital; Internal Medicine, University of Helsinki, Helsinki, Finland

5 Departments of Clinical Nutrition and Obesity Centre, Kuopio University Hospital, Kuopio, Finland
GD. Serum plant sterols, campesterol $(p=0.003)$, sitosterol $(p=0.002)$, and avenasterol $(p=0.015)$, were lower in patients with GD compared to those without GD. This association remained significant after adjustment for NAFLD, use of statin medication, and previous laparoscopic cholecystectomy (LCC). Levels of sitosterol $(p=0.001)$ and campesterol $(p=0.001)$ remained lower in obese individuals with GD also after obesity surgery. Liver mRNA expression of genes regulating cholesterol synthesis and bile metabolism was increased in individuals with GD.

Conclusions Serum plant sterols were lower in patients with GD independent of NAFLD, history of LCC, use of statin medication, and weight loss after LRYGB. Low serum plant sterols in patients with GD suggest potentially inherited alterations in sterol absorption and biliary transport in subjects susceptible for GD.

Keywords Laparoscopic roux-en-Y gastric bypass - Obesity · Statins $\cdot$ Gallstones $\cdot$ Weight loss $\cdot$ Plant sterols

\section{Introduction}

The rising prevalence of gallstone disease (GD) in western countries has been associated with increasing prevalence of obesity. Other known risk factors are female gender, aging, metabolic syndrome, and rapid weight loss [1]. Given the similar associations with obesity and dyslipidemia [2,3], it is not surprising that non-alcoholic fatty liver disease (NAFLD) and GD have both been associated with high incidence of cardiovascular disease (CVD) [4]. Accordingly, previous studies have shown that about $20 \%$ of GD patients have NAFLD [5-9] and GD has been proposed to be an independent risk factor for NAFLD [10]. It is not yet clear whether NAFLD is 
a precursor of GD or whether the presence of GD possibly indicates the presence of long-standing features of metabolic syndrome that accelerates the progression of NAFLD [4]. For example, the mechanism leading to altered bile metabolism in NAFLD and GD may partially be shared [4, 9]. It has been shown that both GD and NAFLD associate with lower levels of plant sterols and higher levels of cholesterol precursors in serum $[11,12]$. Finally, a significantreduction in theincidence of symptomatic GD has been observed in patients using statin therapy blocking cholesterol synthesis [13].

Both at the intestinal level and in the liver sterol, transporters regulate the transport of cholesterol and noncholesterol sterols. For example, Niemann-Pick C1-like 1 (NPC1L1) and ATP-binding cassette G5/8 (ABCG5/8) transport both cholesterol and plant sterols, e.g., sitosterol and campesterol[14]. They regulate theamountofsterols excreted into bile $[15,16]$ and sterol uptake from the gut [15]. As plant sterols are not synthesized in the human body, their serum levels have been used to estimate the function of hepatic and intestinal cholesterol transporters [14]. Interestingly, variants in the $A B C G 5 / 8$ transporters that associate with changes in sterol transportalso contribute to cholesterol gallstone formation suggesting a common etiology [17-20].

It is not known whether the association between GD and low levels of serum plant sterols is explained by associated NAFLD and whether this association persists afterweightloss known to change bile metabolism and risk of GD. Therefore, the aim of our study was to investigate if the lower levels of serumplantsterolsin obese individuals with GD are explained by NAFLD. We also investigated if weight loss induced by laparoscopic Roux-en-Y gastric bypass (LRYGB) that is known to ameliorate NAFLD [21] and decrease absorption of sterols [22] changes this relationship. To this aim, we assessed serum and bile non-cholesterol sterols in obese patients with ( $n=95)$ and without ( $n=147)$ GD. Importantly, we also had liver histology available to diagnose NAFLD. We also analyzed the association between GD and the expression of genes regulating sterol and lipid metabolism in the liver.

\section{Materials and Methods}

\section{Study Population}

The patients accepted to obesity surgery at Kuopio University Hospital have been recruited to the Kuopio Obesity Surgery Study (KOBS) since 2005 [23]. All patients met the National Institutes of Health guidelines for bariatric surgery [24]. From May 2005 to November 2013, a total of 242 morbidly obese individuals ( 65 men and 177 women, $47.7 \pm 8.5$ years, BMI $43.4 \pm 5.1 \mathrm{~kg} / \mathrm{m}^{2}$ ) were included to the KOBS. All patients were instructed to follow a very low calorie diet (VLCD) for 4-5 weeks with the aim to reach $10 \%$ weight loss preoperatively. Clinical characteristics, possible previous laparoscopic cholecystectomy (LCC), and the use of cholesterollowering medication were recorded (Supplementary Table 1).

The incidence of early and late postoperative complications after LRYGB was at the same level compared to international experiences (Supplementary Table 2). Ultrasound of the gallbladder was performed before the operation to diagnose GD [25]. The study was approved by the Ethics Committee of the Northern Savo Hospital District (54/ 2005, 104/2008 and 27/2010).

\section{Laboratory Determinations}

Plasma glucose was measured by enzymatic hexokinase photometric assay (Konelab Systems Reagents, Thermo Fischer Scientific, Vantaa, Finland). Glucose tolerance was classified according to the ADA criteria [26] using fasting values. Serum insulin was determined by immunoassay (ADVIA Centaur Insulin IRI, no 02,230,141, Siemens Medical Solutions Diagnostics, Tarrytown, NY). Cholesterol, HDL cholesterol, and triglyceride levels from serum were assayed by standard automated enzymatic methods (Roche Diagnostics, Mannheim, Germany).

\section{Serum and Bile Non-Cholesterol Sterols}

Non-cholesterol sterols in serum and bile were measured with gas liquid chromatography (GLC) on a 50-m capillary column (Ultra 2; Agilent Technologies, Wilmington, DE) using $5 \alpha$-cholestane as the internal standard [27]. Serum cholesterol precursors squalene, cholestenol, desmosterol, and lathosterol reflect whole-body cholesterol synthesis, whereas serum cholestanol and plant sterols campesterol, sitosterol, and avenasterol reflect cholesterol absorption efficiency [28]. The non-cholesterol sterol values in serum and bile are given as ratios to cholesterol of the same GLC run $\left(10^{2} \times \mathrm{mmol} / \mathrm{mol}\right.$ of cholesterol $)$.

\section{Liver Biopsies and Bile Fluid Sample}

Liver biopsies were obtained using Trucut needle (Radiplast $\mathrm{AB}$, Uppsala, Sweden) or with the ultrasonic scissors during the elective LRYGB operation from all the patients participating in the KOBS study. The histological assessment of NAFLD was performed by one pathologist according to Brunt et al. [29]. Chronic hepatitis B and C were excluded using serology if ALT values were elevated prior to surgery. Hemochromatosis was excluded by the histological analysis of liver biopsies and by normal serum ferritin levels in subjects that had elevated serum ALT level. Bile fluid was taken transhepatically from the gallbladder with a fine needle aspiration during the operation. 


\section{Liver Gene Expression Using TruSeq-Targeted RNA Expression (TREx)}

All liver samples for gene expression analysis were immediately frozen in liquid nitrogen. Total RNA from liver tissue was extracted using Tri-Reagent (Applied Biosystems (ABI) Foster City, CA, USA). TruSeq-Targeted RNA Expression (Illumina, San Diego, CA, USA) was used for measuring the gene expression levels of genes related to cholesterol, bile acid, and lipid metabolism (Supplementary Table 3) in the human liver according to instructions provided by the manufacturer using MiSeq system (Illumina). Total RNA (150 ng) was reverse-transcribed using the ProtoScript II Reverse Transcriptase (New England BioLabs). Oligo pool-targeted regions of interest were hybridized to complementary DNA (cDNA). Next, hybridized cDNA was extended by DNA polymerase followed by ligation using DNA ligase. The extension-ligation products were amplified with PCR, and AMPure XP beads (Beckman Coulter) were used to clean up the $\mathrm{PCR}$ products. Equal volumes of the products were pooled together and quantitated with DNA 1000 chip (Agilent Technologies). Finally, the pooled sample was diluted, denatured, and sequenced with MiSeq.

\section{Statistical Analyses}

Statistical analyses were performed using the SPSS statistical software for Windows (version 19.0, SPSS, Chicago, IL). Data are given as means $\pm \mathrm{SD}$ and $p<0.05$ was considered statistically significant. General linear model (GLM) univariate analyses were used to study the differences between the study groups (adjusted for sex, BMI, and use of statin, when appropriate) (Tables 1 and 2 and Supplementary Table 5). Independent samples $T$ test was used to compare the changes during the year after surgery between the study groups (Table 2). In addition, paired samples $\mathrm{T}$ test was used to assess the significance of changes in response to obesity surgery (Supplementary Table 4). For the TREx analysis, the expression levels for each gene per sample in the gene panel were normalized based on the total number of aligned reads of the corresponding sample and the results are shown as percentage of total transcript reads. Independent samples $T$ test was used to compare gene expression levels between the study groups (statin users were excluded from the analysis).

\section{Results}

Clinical characteristics of 242 individuals participating in this study are shown in Supplementary Table 1 (65 men and 177 women, age $47.7 \pm 8.5$ years and range $27-65$ years, respectively; weight $123.8 \pm 17.8 \mathrm{~kg}$, range $83-176 \mathrm{~kg}$; body mass index (BMI) $43.4 \pm 5.1 \mathrm{~kg} / \mathrm{m}^{2}$, range $33-63 \mathrm{~kg} / \mathrm{m}^{2}$ ). Forty percent had
GD $(n=95)$ and 29\% (n=71) used statins before the operation. GD was more common among female patients $(p=0.0006)$ and associated with lower weight $(p=0.002)$ and total serum cholesterol $(p=0.018)$ (Table 1). We divided participants with GD further to those who had underwent LCC $(n=51)$ and to those who had not $(n=44)$ (flow chart in Fig. 1).

\section{Serum Non-Cholesterol Sterols}

First, we analyzed serum non-cholesterol sterol values before and 1 year after LRYGB in those with or without GD. Serum plant sterols campesterol $(p=0.003)$, sitosterol $(p=0.002)$, and avenasterol $(p=0.015)$ ratios to cholesterol were lower in patients with GD compared to those without GD (Table 2 and Supplementary Fig. 1A), and this association remained significantafteradjustmentforNAFLD (Table2). This difference remained significant 1 year after LRYGB for campesterol $(p=0.001)$ and for sitosterol $(p=0.001)$ but not for avenasterol ratios $(p=0.197)$ (Table 2 and Supplementary Fig. 1B). It is important to note that these differences in serum sitosterol and campesterol ratios remained after obesity surgery despite a significant decrease in both of these in response to surgery (Table 2). Furthermore, use of statins did not affect the results (use of statins was adjusted for in Table 2 and Supplementary Fig. 1). The levels of non-cholesterol sterol ratios were not affected by LCC (Fig. 2 and Supplementary Table 4). The only difference in cholesterol precursor ratios was higher lathosterol ratios in those with GD after surgery (Table 2 and Supplementary Fig. 1B).

\section{Bile Non-Cholesterol Sterols and Liver mRNA Expression}

The ratios of bile non-cholesterol sterols did not differ between those with and without GD (Supplementary Table 5). However, the liver expression of genes regulating cholesterol export(ABCG8), LDL uptake (PCSK9), cholesterol synthesis (HMGCR, DHCR24, MSMO1, and TM7SF2), and bile acid exporter $(A B C B 11$ and $A B C C 2)$ were increased in those with GD compared to those without GD (Fig. 3). Results of all genes are shown in Supplementary Table 3. Individuals using statins were excluded from the mRNA expression analysis.

\section{Discussion}

Our aim was to investigate the changes in plant sterol metabolism in relation to GD in obese individuals, taking account the effect of NAFLD and obesity surgery. First, there was no difference in liver histology between those with and without GD, suggesting that any differences between the groups in serum sterols are not related to NAFLD. Second, we found that the levels of serum sitosterol and campesterol remained low after obesity surgery in those with GD despite a 
Table 1 Characteristics of the study subjects divided by the presence of gallstone disease at baseline

\begin{tabular}{|c|c|c|c|c|}
\hline & \multicolumn{2}{|c|}{ Gallstone disease $(n=242) \mathrm{s}$} & \multirow[t]{2}{*}{$P$ value $^{\mathrm{a}}$} & \multirow[t]{2}{*}{ Adjusted $P$ value ${ }^{\mathrm{b}}$} \\
\hline & No $(n=147)$ & Yes $(n=95)$ & & \\
\hline Gender (male/female) & $53 / 94$ & $12 / 83$ & 0.0006 & \\
\hline Age (years) & $47.0 \pm 8.3$ & $48.9 \pm 8.4$ & 0.078 & \\
\hline Weight (kg) & $126.6 \pm 18.6$ & $119.4 \pm 15.9$ & 0.002 & \\
\hline Body mass index $\left(\mathrm{kg} / \mathrm{m}^{2}\right)$ & $43.6 \pm 5.0$ & $43.0 \pm 5.2$ & 0.314 & \\
\hline $\begin{array}{l}\text { Fasting plasma glucose } \\
(\mathrm{mmol} / \mathrm{L})\end{array}$ & $6.7 \pm 2.1$ & $6.3 \pm 1.7$ & 0.066 & 0.318 \\
\hline $\begin{array}{l}\text { Fasting serum insulin } \\
\quad(\mathrm{pmol} / \mathrm{L})\end{array}$ & $142.8 \pm 196.2$ & $178.2 \pm 441.6$ & 0.480 & 0.260 \\
\hline $\begin{array}{l}\text { Total serum cholesterol } \\
\quad(\mathrm{mmol} / \mathrm{L})\end{array}$ & $4.3 \pm 1.0$ & $4.1 \pm 1.0$ & 0.063 & 0.018 \\
\hline $\begin{array}{l}\text { Serum triglycerides } \\
(\mathrm{mmol} / \mathrm{L})\end{array}$ & $1.7 \pm 1.0$ & $1.5 \pm 0.7$ & 0.079 & 0.189 \\
\hline $\begin{array}{l}\text { HDL cholesterol } \\
\qquad(\mathrm{mmol} / \mathrm{L})\end{array}$ & $1.2 \pm 0.7$ & $1.1 \pm 0.3$ & 0.508 & 0.238 \\
\hline $\operatorname{ALT}(\mathrm{U} / \mathrm{L})$ & $44.9 \pm 31.3$ & $42.0 \pm 23.3$ & 0.475 & 0.771 \\
\hline $\begin{array}{l}\text { Use of cholesterol } \\
\text { medication }(\%)\end{array}$ & $33 \%$ & $23 \%$ & 0.090 & \\
\hline Steatosis grade $(n)$ & 119 & 82 & 0.010 & 0.003 \\
\hline$<5 \%$ & $37(31 \%)$ & $37(45 \%)$ & & \\
\hline $5-33 \%$ & $40(34 \%)$ & $33(40 \%)$ & & \\
\hline $33-66 \%$ & $22(18 \%)$ & $8(10 \%)$ & & \\
\hline$>66 \%$ & $20(17 \%)$ & $4(5 \%)$ & & \\
\hline Lobular inflammation $(n)$ & 119 & 82 & 0.010 & 0.010 \\
\hline None & $63(53 \%)$ & $60(73 \%)$ & & \\
\hline$<2$ foci per $200 \times$ field & $40(34 \%)$ & $18(22 \%)$ & & \\
\hline $2-4$ foci per $200 \times$ field & $16(13 \%)$ & $4(5 \%)$ & & \\
\hline$>4$ foci per $200 \times$ field & 0 & 0 & & \\
\hline Fibrosis $(n)$ & 119 & 82 & 0.419 & \\
\hline 0 & $58(49 \%)$ & $47(57 \%)$ & & \\
\hline 1 & $54(45 \%)$ & $32(39 \%)$ & & \\
\hline 2 & $4(3 \%)$ & $1(1 \%)$ & & \\
\hline 3 & $3(3 \%)$ & $1(1 \%)$ & & \\
\hline 4 & 0 & $1(1 \%)$ & & \\
\hline Ballooning $(n)$ & 119 & 82 & 0.292 & \\
\hline None & $79(66 \%)$ & $62(76 \%)$ & & \\
\hline Few balloon cells & $38(32 \%)$ & $18(22 \%)$ & & \\
\hline Many cells/prominent & $2(2 \%)$ & $2(2 \%)$ & & \\
\hline Liver phenotype $(n)$ & 77 & 55 & 0.098 & \\
\hline Normal liver & $28(36 \%)$ & $30(55 \%)$ & & \\
\hline Simple steatosis & $18(23 \%)$ & $11(20 \%)$ & & \\
\hline NASH & $31(40 \%)$ & $14(25 \%)$ & & \\
\hline
\end{tabular}

Mean \pm SD shown. $P$ values $<0.05$ are bolded

$A L T$ serum alanine aminotransferase, $N A S H$ nonalcoholic steatohepatitis

${ }^{\text {a }}$ Independent samples $T$ test for continuous and chi-square test for categorical variables

${ }^{\mathrm{b}}$ Adjusted for sex, BMI, and statin use significant decrease in both weight and serum plant sterols in response to surgery, as published before by our group [22]. This suggested an association of GD with low serum plant sterols independent of obesity. Furthermore, the association of low sitosterol and campesterol with GD was not explained by previous LCC known to change bile metabolism [30]. 


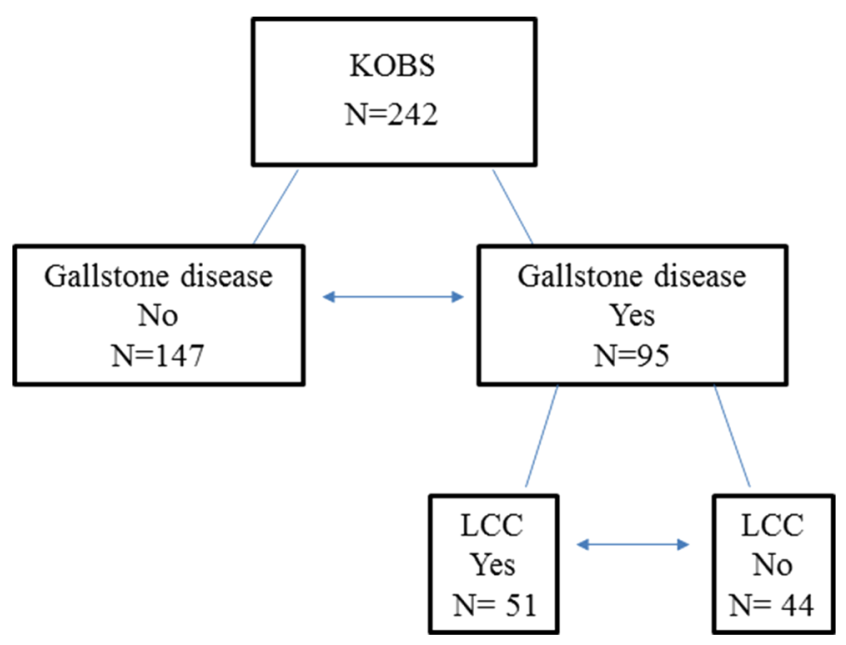

Fig. 1 Graph demonstrating the comparisons between different study groups of Kuopio Obesity Surgery Study (KOBS). The main comparison was between those with and without gallstone disease (GD). Furthermore, we investigated if previous laparoscopic cholecystectomy (LCC) had an effect in those with GD

Our findings that low plant sterol levels in individuals with GD were observed both before and after obesity surgery, in those with and without previous LCC, and independent of
NAFLD, support the conclusion that cholesteroland plantsterolmetabolismare primarilyaltered in GD. Theseresults are in line with the results from Krawczyk et al. [11] who also found that serum sterols were lower in patients with GD compared to those without GD. These results also support the idea that low levels of serumplantsterols are related to GDitself, potentially partly due to genetic regulation by $A B C G 5 / 8$ genes $[17,19,20$, 31].

To further investigate the role of sterol transporters in GD, we investigated the liver mRNA expression of genes regulating sterol export, cholesterol metabolism, and bile metabolism. Enhanced hepatic protein expression of $A B C G 5 / 8$ has been described in individuals with GD [32], and functional studies have demonstrated that biliary cholesterol secretion correlates with hepatic expression of $A B C G 5 / G 8[33,34]$. Accordingly, we found an increased expression of $A B C G 8$ in those with GD. The increased expression of genes regulating cholesterol synthesis is also in line with previous observations reporting increased cholesterol synthesis in GD [11, 35]. The increased expression of PCSK9, encoding a protein regulating LDL receptor levels, in individuals with GD could theoretically contribute to elevated cholesterol levels. Despite the increase in expressions of $A B C B 11$ and $A B C C 2$, we did not

Table 2 Serum non-cholesterol sterols and sitostanol in participants of the Kuopio Obesity Surgery Study (KOBS) at baseline and at one-year followup divided by the presence of gallstone disease

\begin{tabular}{|c|c|c|c|c|c|c|c|}
\hline & Baseline & & $P$ value ${ }^{\mathrm{a}}$ & Adjusted $P$ value ${ }^{\mathrm{b}}$ & Follow up & & $P$ value $^{\mathrm{a}}$ \\
\hline Gallstone disease & No $(n=147)$ & Yes $(n=95)$ & & & No $(n=147)$ & Yes $(n=95)$ & \\
\hline Gender (male/female) & $53 / 94$ & $12 / 83$ & 0.0006 & & & & \\
\hline Age (years) & $47.0 \pm 8.3$ & $48.9 \pm 8.4$ & 0.078 & & & & \\
\hline Weight $(\mathrm{kg})$ & $126.6 \pm 18.6$ & $119.4 \pm 15.9$ & 0.002 & 0.948 & $100.4 \pm 17.3$ & $94.1 \pm 13.7$ & 0.034 \\
\hline Body mass index $\left(\mathrm{kg} / \mathrm{m}^{2}\right)$ & $43.6 \pm 5.0$ & $43.0 \pm 5.2$ & 0.314 & 0.269 & $33.9 \pm 4.6$ & $34.3 \pm 6.3$ & 0.726 \\
\hline Fasting plasma glucose $(\mathrm{mmol} / \mathrm{L})$ & $6.7 \pm 2.1$ & $6.3 \pm 1.7$ & 0.066 & 0.318 & $5.8 \pm 1.2$ & $5.5 \pm 0.9$ & 0.072 \\
\hline Fasting serum insulin $(\mathrm{pmol} / \mathrm{L})$ & $142.8 \pm 196.2$ & $178.2 \pm 441.6$ & 0.480 & 0.260 & $63.0 \pm 60.0$ & $60.0 \pm 48.0$ & 0.797 \\
\hline Total serum cholesterol $(\mathrm{mmol} / \mathrm{L})$ & $4.3 \pm 1.0$ & $4.1 \pm 1.0$ & 0.063 & 0.018 & $4.5 \pm 1.0$ & $4.5 \pm 0.8$ & 0.568 \\
\hline Serum triglycerides $(\mathrm{mmol} / \mathrm{L})$ & $1.7 \pm 1.0$ & $1.5 \pm 0.7$ & 0.079 & 0.189 & $1.2 \pm 0.4$ & $1.1 \pm 0.4$ & 0.088 \\
\hline HDL cholesterol $(\mathrm{mmol} / \mathrm{L})$ & $1.2 \pm 0.7$ & $1.1 \pm 0.3$ & 0.508 & 0.238 & $1.5 \pm 0.4$ & $1.5 \pm 0.4$ & 0.762 \\
\hline Cholestanol & $154 \pm 34$ & $150 \pm 73$ & 0.632 & 0.748 & $157 \pm 33$ & $144 \pm 54$ & 0.114 \\
\hline Campesterol & $178 \pm 85$ & $125 \pm 54$ & 0.0003 & 0.003 & $143 \pm 61$ & $106 \pm 39$ & 0.001 \\
\hline Sitosterol & $85 \pm 45$ & $59 \pm 24$ & 0.0004 & 0.002 & $67 \pm 30$ & $49 \pm 20$ & 0.001 \\
\hline Sitostanol & $7 \pm 2$ & $7 \pm 2$ & 0.905 & 0.601 & $8 \pm 3$ & $7 \pm 2$ & 0.253 \\
\hline Avenasterol & $29 \pm 9$ & $25 \pm 6$ & 0.018 & 0.015 & $24 \pm 9$ & $22 \pm 6$ & 0.197 \\
\hline Squalene & $15 \pm 8$ & $14 \pm 7$ & 0.357 & 0.223 & $12 \pm 8$ & $12 \pm 6$ & 0.938 \\
\hline Cholestenol & $26 \pm 15$ & $30 \pm 18$ & 0.192 & 0.385 & $22 \pm 18$ & $24 \pm 17$ & 0.433 \\
\hline Desmosterol & $86 \pm 32$ & $111 \pm 101$ & 0.046 & 0.115 & $83 \pm 30$ & $99 \pm 76$ & 0.115 \\
\hline Lathosterol & $173 \pm 82$ & $194 \pm 79$ & 0.172 & 0.843 & $123 \pm 55$ & $152 \pm 57$ & 0.010 \\
\hline
\end{tabular}

$P$ values $<0.05$ are bolded. Serum non-cholesterol sterols and sitostanol values are expressed as ratios to serum total cholesterol $\left(10^{2} \mathrm{mmol} / \mathrm{mol}\right.$ of cholesterol)

${ }^{\mathrm{a}}$ Independent samples $\mathrm{T}$ test for continuous and chi-square test for categorical variables

${ }^{\mathrm{b}}$ Adjusted for sex, BMI, statin use, and histology 

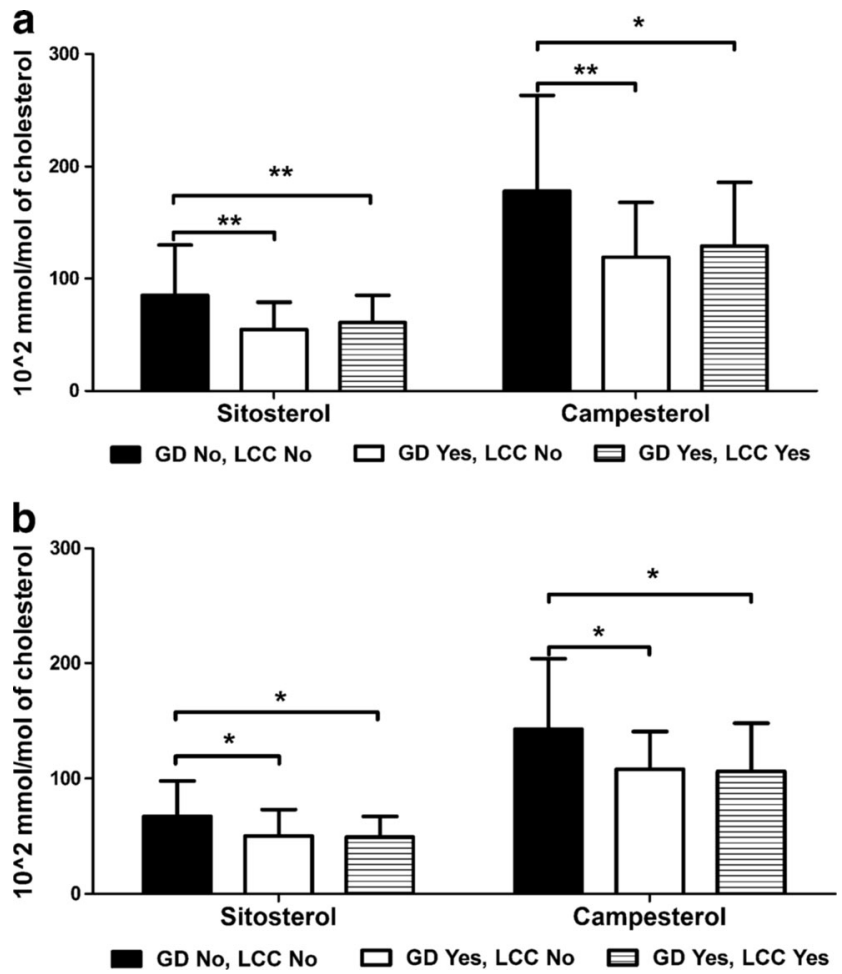

Fig. 2 Serum sitosterol and campesterol values $\left(10^{2} \mathrm{mmol} / \mathrm{mol}\right.$ of cholesterol) in study groups divided by the presence of gallstone disease (GD) at baseline (panel A) and at 1-year follow-up (panel B) after the obesity surgery. Those with GD have also been divided to those who have and have not been operated with laparoscopic cholecystectomy (LCC). General linear model, adjusted for sex, body mass index, and use of statin medication. * $P<0.05$; ** $P<0.01$. Data is presented as mean \pm standard deviation

observe any association of GD with bile plant sterols, contrary to what was published before that bile plant sterols are increased in those with GD by Krawczyk et al. [11].

Statin medication in the prevention of cardiovascular diseases and cerebrovascular events has rapidly become more common [36,37]. The use of statin medication is based on its ability to inhibit cholesterol synthesis in liver which will diminish cholesterol concentration in bile [38]. Several studies have reported a significant reduction in the incidence of symptomatic gallstone disease in patients using statin therapy [13]. However, most human studies do not find that statin monotherapy would lead to the complete dissolution of gallstones [39]. The risk of developing symptoms or complications related to gallstones, approximately $1-4 \%$ per year [ 40 , $41]$, can be reduced by statins $[42,43]$. Therefore, we adjusted all our analysis by the use of statins although the use of statins did not significantly differ between the study groups in our study (Table 1). Thus, the associations between GD and sterol metabolism in our study cannot be explained by the use of statins.

Our study has some limitations. First, we acknowledge that heterogeneity between the individuals may exist and that our sample size was too small to study potential differences in sterol metabolism between individuals with different risk factors for GD (e.g., in men and women separately). Specifically, we acknowledge that our study is too small to properly investigate the potential modifying role of genetic $A B C G 5 / 8$ variants in the association between GD and sterol metabolism. On the other hand, the strength of our analysis was that we had a detailed metabolic characterization, liver histology, and mRNA analysis as well as perioperative bile fluid samples.

In conclusion, we demonstrate that serum plant sterols are lower in individuals with GD compared to those without, independent of weight loss, NAFLD, previous LCC, and use of statins. The mechanism remains open but could be linked with potentially inherited alterations in sterol absorption in the intestines and transport in the liver in those susceptible for GD. Through these mechanism, the persistence of low serum plant sterols in patients with GD after surgery could also partially contribute to increased prevalence of gallstones after surgery.

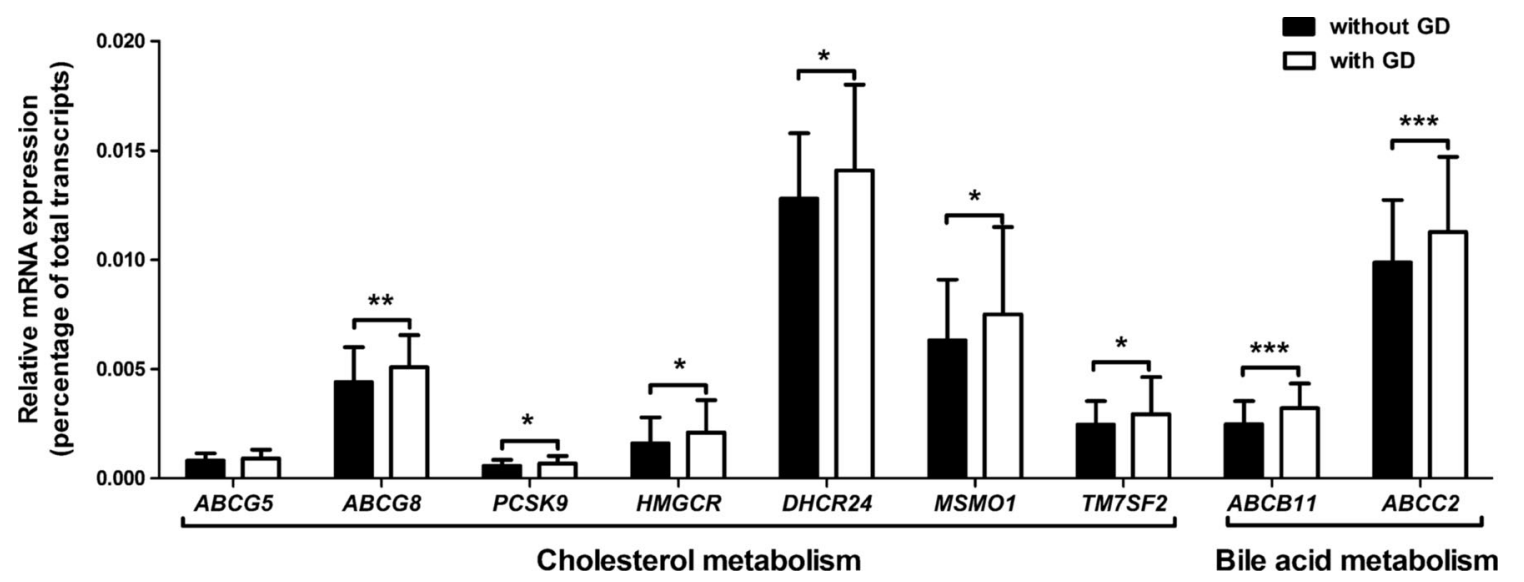

Fig. 3 The expression of genes related to cholesterol and bile acid metabolism in the liver of the participants of the Kuopio Obesity Surgery Study divided to those with and without gallstone disease (GD) after the

obesity surgery. Independent samples $T$ test was used for comparing the gene expression levels between study groups; $* P<0.05$; ** $P<0.01$; *** $P<0.0001$. Data is presented as mean \pm standard deviation 
Acknowledgments We thank Matti Laitinen, Päivi Turunen, and Leena Kaipiainen for their careful work in patient recruitment and laboratory analyses.

\section{Compliance with Ethical Standards}

Conflicts of Interest The authors declare that they have no conflict of interest.

Ethical Approval All procedures performed in studies involving human participants were in accordance with the ethical standards of the institutional and/or national research committee and with the 1964 Helsinki Declaration and its later amendments or comparable ethical standards.

Informed Consent Informed consent was obtained from all individual participants included in the study.

\section{References}

1. Shaffer EA. Gallstone disease: epidemiology of gallbladder stone disease. Best Pract Res Clin Gastroenterol. 2006;20(6):981-96.

2. Abrams GA, Kunde SS, Lazenby AJ, et al. Portal fibrosis and hepatic steatosis in morbidly obese subjects: a spectrum of nonalcoholic fatty liver disease. Hepatology. 2004;40(2):475-83.

3. Xanthakos S, Miles L, Bucuvalas J, et al. Histologic spectrum of nonalcoholic fatty liver disease in morbidly obese adolescents. Clin Gastroenterol Hepatol. 2006;4(2):226-32.

4. Ahmed MH, Ali A. Nonalcoholic fatty liver disease and cholesterol gallstones: which comes first? Scand J Gastroenterol. 2014;49(5): 521-7. doi:10.3109/00365521.2014.894119.

5. Loria P, Lonardo A, Lombardini S, et al. Gallstone disease in nonalcoholic fatty liver: prevalence and associated factors. J Gastroenterol Hepatol. 2005;20:1176-84.

6. Fracanzani AL, Valenti L, Russello M, et al. Gallstone disease is associated with more severe liver damage in patients with nonalcoholic fatty liver disease. PLoS One. 2012;7(7):e41183.

7. Roesch-Dietlen F, Pérez-Morales A, Melo-Santisteban G, et al. Frequency and clinical, biochemical and histological characteristics of nonalcoholic fatty liver disease in patients with gallstone disease. Cir Cir. 2008;76:37-42.

8. la Ramos-De MA, Remes-Troche JM, Roesch-Dietlen FB, et al. Routine liver biopsy to screen for nonalcoholic fatty liver disease (NAFLD) during cholecystectomy for gallstone disease: is it justified? J Gastrointest Surg. 2008;12:2097-102.

9. Krawczyk M, Bonfrate L, Portincasa P. Nonalcoholic fatty liver disease. Best Pract Res Clin Gastroenterol. 2010;24:695-708.

10. Koller T, Kollerova J, Hlavaty T, et al. Cholelithiasis and markers of nonalcoholic fatty liver disease in patients with metabolic risk factors. Scand J Gastroenterol. 2012;47:197-203.

11. Krawczyk M, Lütjohann D, Schirin-Sokhan R, et al. Phytosterol and cholesterol precursor levels indicate increased cholesterol excretion and biosynthesis in gallstone disease. Hepatology. 2012 May;55(5):1507-17. doi:10.1002/hep.25563.

12. Simonen P, Kotronen A, Hallikainen M, et al. Cholesterol synthesis is increased and absorption decreased in non-alcoholic fatty liver disease independent of obesity. J Hepatol. 2011;54:153-9.

13. Cariati A, Piromalli E. Limits and perspective of oral therapy with statins and aspirin for the prevention of symptomatic cholesterol gallstone disease. Expert Opin Pharmacother. 2012;13(9):1223-7.
14. Miettinen TA, Tilvis RS, Kesäniemi YA. Serum plant sterols and cholesterol precursors reflect cholesterol absorption and synthesis in volunteers of a randomly selected male population. Am J Epidemiol. 1990;131:20-31.

15. Temel RE, Tang W, Ma Y, et al. Hepatic Niemann-pick C1-like 1 regulates biliary cholesterol concentration and is a target of ezetimibe. J Clin Invest. 2007;117(7):1968-78.

16. Berge KE, Tian H, Graf GA, et al. Accumulation of dietary cholesterol in sitosterolemia caused by mutations in adjacent $\mathrm{ABC}$ transporters. Science. 2000;290(5497):1771-5.

17. Renner O, Lütjohann D, Richter D, et al. Role of the ABCG8 19H risk allele in cholesterol absorption and gallstone disease. BMC Gastroenterol. 2013;13:30.

18. Krawczyk M, Wang DQ, Portincasa P, et al. Dissecting the genetic heterogeneity of gallbladder stone formation. Semin Liver Dis. 2011;31:157-72.

19. Buch S, Schafmayer C, Völzke H, et al. A genome-wide association scan identifies the hepatic cholesterol transporter ABCG8 as a susceptibility factor for human gallstone disease. Nat Gen. 2007;39: 995-9.

20. Grunhage F, Acalovschi M, Tirziu S, et al. Increased gallstone risk in humans conferred by common variant of hepatic ATP-binding cassette transporter for cholesterol. Hepatology. 2007;46:793-801.

21. Hannah Jr WN, Harrison SA. Effect of weight loss, diet, exercise and bariatric surgery on nonalcoholic fatty liver disease. Clin Liver Dis. 2016;20(2):339-50. doi:10.1016/j.cld.2015.10.008.

22. Pihlajamäki J, Grönlund S, Simonen M, et al. Cholesterol absorption decreases after roux-en-Y gastric bypass but not after gastric banding. Metabolism. 2010;59(6):866-72. doi:10.1016/j. metabol.2009.10.004.

23. Pihlajamäki J, Kuulasmaa T, Kaminska D, et al. Serum interleukin 1 receptor antagonist as an independent marker of nonalcoholic steatohepatitis in humans. Int J Hepatol. 2012;3:663-70.

24. Conference NIH. Gastrointestinal surgery for severe obesity. Consensus development conference panel. Ann Intern Med. 1991;115:956-61.

25. Chiang WK, Lee FM, Santen S. Cholelithiasis. eMedicine. November 3, 2009. accessed, November 30, 2009.

26. American Diabetes Association. Diagnosis and classification of diabetes mellitus. Diabetes Care. 2004;27:5-10.

27. Miettinen TA. Cholesterol metabolism during ketoconazole treatment in man. J Lipid Res. 1988;29:43-51.

28. Simonen P, Gylling H, Miettinen TA. The validity of serum squalene and non-cholesterol sterols as surrogate markers of cholesterol synthesis and absorption in type 2 diabetes. Atherosclerosis. 2008;197:883-8.

29. Brunt EM, Janney CG, Di Bisceglie AM, et al. Nonalcoholic steatohepatitis: a proposal for grading and staging the histological lesions. Am J Gastroenterol. 1999;94:2467-74.

30. Barrera F, Azócar L, Molina H, et al. Effect of cholecystectomy on bile acid synthesis and circulating levels of fibroblast growth factor 19. Ann Hepatol. 2015;14(5):710-21.

31. Lammert F, Wang DQ. New insights into the genetic regulation of intestinal cholesterol absorption. Gastroenterology. 2005;129:718 34.

32. Jiang ZY, Parini P, Eggertsen G, et al. Increased expression of LXR alpha, ABCG5, ABCG8, and SR-BI in the liver from normolipidemic, nonobese Chinese gallstone patients. J Lipid Res. 2008;49: 464-72.

33. Kosters A, Frijters RJ, Schaap FG, et al. Relation between hepatic expression of ATP-binding cassette transporters G5 and G8 and biliary cholesterol secretion in mice. J Hepatol. 2003;38:710-6.

34. Kamisako T, Ogawa H. Regulation of biliary cholesterol secretion is associated with abcg 5 and abcg8 expressions in the rats: effects of diosgenin and ethinyl estradiol. Hepatol Res. 2003;26:348-52. 
35. Liew PL, Lee WJ, Wang W, et al. Fatty liver disease: predictors of nonalcoholic steatohepatitis and gallbladder disease in morbid obesity. Obes Surg. 2008;18(7):847-53. doi:10.1007/s11695-0079355-0.

36. Patel J, Abd T, Blumenthal RS, et al. Genetics and personalized medicine-a role in statin therapy? Curr Atheroscler Rep. 2014;16(1):384. doi:10.1007/s11883-013-0384-y.

37. Squizzato A, Romualdi E, Dentali F, Ageno W. Statins for acute ischemic stroke. Cochrane Database Syst Rev. 2011;(8): CD007551. doi:10.1002/14651858.CD007551.

38. Smit JW, van Erpecum KJ, Stolk MF, et al. Successful dissolution of cholesterol gallstone during treatment with pravastatin. Gastroenterology. 1992;103:1068-70.
39. HH W, Portincasa P, de Bari O, et al. Prevention of cholesterol gallstones by inhibiting hepatic biosynthesis and intestinal absorption of cholesterol. Eur J Clin Investig. 2013;43(4):413-26.

40. Gurusamy KS, Davidson BR. Surgical treatment of gallstones. Gastroenterol Clin N Am. 2010;39(2):229-44.

41. Portincasa P, Moschetta A, Palasciano G. Cholesterol gallstone disease. Lancet. 2006;368(9531):230-9.

42. Bodmer M, Brauchli YB, Krahenbuhl S, et al. Statin use and risk of gallstone disease followed by cholecystectomy. JAMA. 2009;302(18):2001-7.

43. Tsai CJ, Leitzmann MF, Willett WC, et al. Statin use and the risk of cholecystectomy in women. Gastroenterology. 2009;136(5):1593600 . 